\title{
Unidentified Bright Objects in Neurofibromatosis Type 1
}

Sir,

A 7-yr-boy presented with complaints of generalized tonic-clonic seizures for last 2 yr. Examination revealed multiple cafe-au-lait spots and axillary freckling. Multiple subcutaneous soft swellings were palpable on the trunk, the largest in the paraspinal region measuring $6 \times 6 \mathrm{~cm}$, suggestive of neurofibromas (Fig. 1). MRI brain showed focal rounded lesions in bilateral

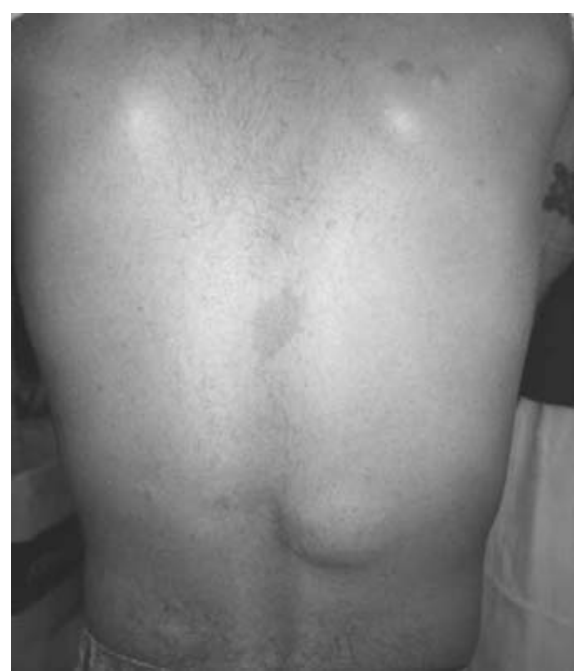

Fig. 1. Note the large paraspinal neurofibroma and multiple cafe-au-lait spots over the back.

basal ganglia appearing hyperintense on $\mathrm{T} 2$ weighted images (Fig. 2) and not showing any enhancement on post contrast images, suggestive of unidentified bright objects (UBO). UBOs are high signal intensity foci seen on T2 weighted sequences, seen in 60-80 percent of patients with Neurofibromatosis Type I (NF1). ${ }^{1}$ These lesions typically appear around $3 \mathrm{yr}$, increase in number and size until 10-12 yr, and then decrease or even disappear. Common locations include basal ganglia, thalami, dentate nucleus of cerebellum and brainstem. Pathologically, these lesions correspond to vacuolar

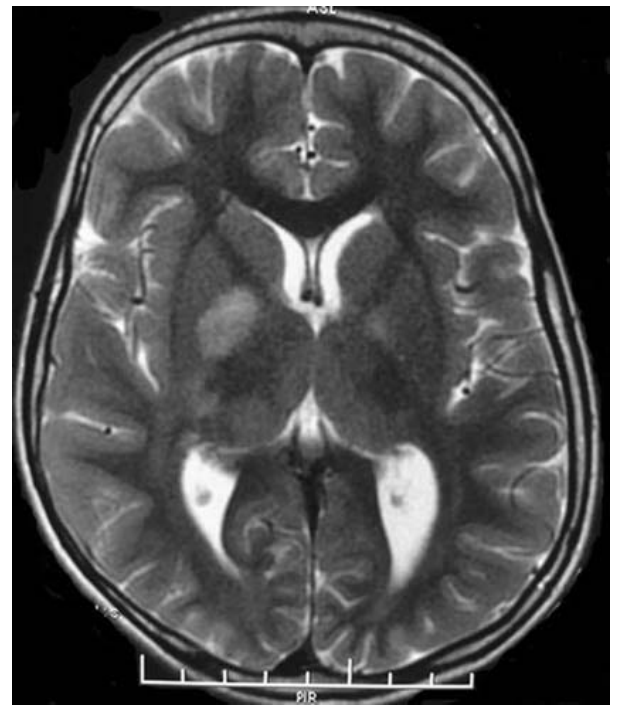

Fig. 2. T2 weighted axial MR image of the brain at the level of basal ganglia shows bilateral focal rounded hyperintense lesions with minimal mass effect.

changes in the myelin sheath. ${ }^{1}$ Even though these lesions generally do not cause neurological symptoms; they have been correlated with learning disabilities. ${ }^{2}$

\section{Anita Choudhary, Suvasini Sharma, Naveen Sankhyan, Sheffali Gulati and Atin Kumar}

Division of Pediatric Neurology, Department of Pediatrics, All India Institute of Medical Sciences,

New Delhi - 110029,

E-mail-sheffaligulati@gmail.com.

[DOI-10.1007/s12098-009-0298-4]

\section{REFERENCES}

1. Lin DDM, Barker PB. Neuroimaging of phakomatoses. Semin Pediatr Neurol 2006; 13: 48-62.

2. Cutting LE, Koth CW, Burnette CP et al. Relationship of cognitive functioning, whole brain volumes, and T2weighted hyperintensities in neurofibromatosis-1. J Child Neurol 2000; 15: 157-160. 